ISSN $0819-2642$

ISBN 9780734037176

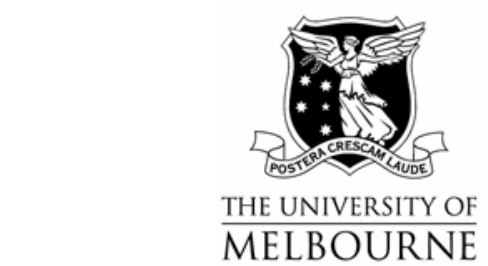

THE UNIVERSITY OF MELBOURNE

DEPARTMENT OF ECONOMICS

RESEARCH PAPER NUMBER 1007

October 2007

\title{
Modelling The Composition of Government Expenditure
} in Democracies

by

John Creedy \&

Solmaz Moslehi

Department of Economics

The University of Melbourne

Melbourne Victoria 3010

Australia. 


\title{
Modelling The Composition of Government Expenditure in Democracies*
}

\author{
John Creedy and Solmaz Moslehi \\ Department of Economics, The University of Melbourne
}

\begin{abstract}
This paper considers whether the ratio of transfer payments to expenditure on public goods in democracies can be explained as the outcome of majority voting. A simple model is constructed in which individuals vote for government expenditure on a public good, for a given income tax rate. The transfer payment is then determined by the government's budget constraint. The equilibrium ratio of transfers to public good expenditure per person is expressed as a quadratic function both of the ratio of the median to the mean wage, and of the tax rate. Data for 29 democratic countries are used to estimate a cross-sectional regression. The empirical results confirm that reductions in the skewness of the wage rate distribution are associated with reductions in transfer payments relative to public goods expenditure, at a decreasing rate. Furthermore, increases in the tax rate, from relatively low levels, are associated with increases in the relative importance of transfer payments. But beyond a certain level, further tax rate increases are associated with a lower ratio of transfers to public goods.
\end{abstract}

${ }^{*}$ We are grateful to Shuyun May Li for comments on an earlier version of this paper. 


\section{Introduction}

The aim of this paper is to explore the extent to which the composition of government expenditure in democracies can be explained as the outcome of majority voting. Special attention is given to the division between expenditure on public goods and on transfer payments. In order to guide the specification of a relationship that can be estimated using information on a cross section of democratic countries, a simple model is constructed in which individuals with similar preferences, but differing abilities and thus wages, vote for government expenditure on a public good. The choice is made conditional on the tax rate in a proportional income tax. ${ }^{1}$ Hence voting is over only one dimension and a majority voting equilibrium is known to exist if certain well-known conditions apply. ${ }^{2}$ The resulting level of a transfer payment, in the form of a basic income, is given by the government's budget constraint. The framework of analysis is entirely static, so that current government expenditure is financed only by current tax revenue. Despite the simplicity of the model, it is seen to provide useful insights into the various relationships involved in voting over the composition of expenditure.

The analysis contrasts with earlier studies which have tended to concentrate on the majority choice of transfer payments, and thus on the relationship between fundamental inequality in the wage rate distribution and desired redistribution of net income achieved through a tax and transfer system. ${ }^{3}$ In those models, the redistribution usually arises entirely from the self-interest of voters who balance the desire for a higher transfer payment

\footnotetext{
${ }^{1}$ Bearse et al. (2001), who examine majority voting over a uniform transfer and public education, also assume that the tax rate is given exogenously. Tridimias and Winer (2005) consider voting over only tax-financed public goods. On difficulties raised by multidimentional voting, see Muller (2003, pp. 87-92). However, Appendix C considers the choice of tax rate in a two-stage framework.

${ }^{2}$ These include single-peakedness of preferences or agent monotonicity, whereby the rankings of individuals are not affected by the tax structure: see Roberts (1977).

${ }^{3} \mathrm{~A}$ large literature is associated with the Romer (1975), Roberts (1977), MeltzerRichard (1981) framework involving majority voting over a linear tax. On voting over redistributive taxation see also Krusell et al. (1999) and Azzimonti et al. (2006). See also the survey by Borck (2007), who gives special attention to models which modify the extent to which inequality may lead to a majority equilibrium involving higher taxation (and thus redistribution via a transfer payment).
} 
against the limits on the government's ability to redistribute income, which are imposed by labour supply incentive effects. ${ }^{4}$ In the present model, the existence of expenditure on public goods, which affects individuals' utility directly, creates a further trade-off. The benefits of higher transfer payments, which (via individuals' budget constraints) allow the consumption of more goods and leisure, are balanced against the desire for public goods which enter utility functions but are subject to a tax price rather than a consumer price. In addition, the present analysis considers the potential effects of an altruistic desire for redistribution on the part of voters.

The basic model and framework of analysis are described in Section 2, which derives the indirect utility function of each individual, expressed in terms of expenditure on the public good and the given tax rate. Section 3 shows that the conditions for a majority voting equilibrium are satisfied, and generates closed-form solutions for public good expenditure and the implied transfer payment. The solutions depend on the ratio of median to arithmetic mean wage rates. The potential effects of an aversion on the part of voters for inequality in the distribution of net income are investigated in Section 4 . Section 5 reports numerical examples. In particular the relationship between the composition of expenditure and the ratio of the median to the average wage rate, and the income tax rate, are investigated. The numerical examples are useful in view of the high degree of nonlinearity involved in the analytical expressions, so that the relationships are not transparent. Furthermore, the numerical examples demonstrate relatively little sensitivity of the voting equilibrium composition of expenditure in relation to inequality aversion on the part of voters. The results of Section 5 are then used to guide the empirical work of Section 6 . The construction of a special cross-sectional dataset for 29 democratic countries, along with estimation of the ratio of median to arithmetic mean wage rates, is described. The resulting regression analyses provide tentative support for the model. Conclusions are in Section 7.

\footnotetext{
${ }^{4}$ In the standard linear tax model, the majority voting equilibrium is characterised by equality between the elasticity of average (gross) earnings with respect to the tax rate and a measure of inequality of earnings (equal to 1 minus the ratio of median earnings to average earnings). This result is a straightforward modification of the optimal tax result obtained by Tuomala (1985).
} 


\section{The Basic Model}

This section derives individuals' preferences for public good expenditure, given the income tax rate. The direct utility function and optimal consumption and labour supply, for an individual who faces a given wage rate and tax rate and receives a non means-tested transfer payment, or basic income, are examined in subsection 2.1. The government budget constraint, derived in subsection 2.2, means that a degree of freedom in policy choices is lost and the value of the unconditional transfer payment is determined for a given tax rate and level of public good provision. Hence, as shown in subsection 2.3 , the indirect utility function can be expressed in terms of public good expenditure and the tax rate in this static model. ${ }^{5}$ Earnings are the only source of income and tax revenue is devoted only to the provision of the pure public good and the transfer payment.

\subsection{Individual Consumption and Labour Supply}

Each individual is assumed to derive utility from consumption, $c$, leisure, $h$, and the public good, $G$. By definition all individuals consume the same amount of the public good which must be tax-financed. The direct utility function is assumed to be Cobb-Douglas, so that (omitting individual subscripts):

$$
U=c^{\alpha} h^{\beta} G^{1-\alpha-\beta}
$$

Suppose that individuals have similar preferences but different productivities and therefore wage rates, $w$. Although all individuals consume the same amount of the public good, they do not receive the same benefits: higher wage individuals experience higher marginal utility. The model has the property of 'hierarchical adherence' (or 'agent monotonicity'), so that the tax rate does not affect the ranking of individuals by income. High wage individuals are consistently better off in terms of utility, so there is incentive compatibility.

\footnotetext{
${ }^{5}$ The model therefore ignores the effect of government policies on saving. In a dynamic context, complexities can arise from changes in the identity of the median voter and intergenerational conflict, commitment and time consistency. On dynamic voting models, see Krusell et al. (1999), Tabellini and Alesina (1990), Hassler et al. (2005), Azzimonti et al. (2006) and Hassler et al. (2007).
} 
The choice of $G$ is not determined at the individual level, since individuals cannot be excluded, but is determined along with the tax system via a democratic process. The price of the consumption good is normalised to unity, so that consumption and net earnings are equal. Suppose there is an unconditional and untaxed transfer payment of $b$ per individual. There is a simple proportional income tax, with the rate, $t$, so that the price of leisure is $w(1-t)$. Therefore the form of individual's budget constraint is:

$$
c=w(1-h)(1-t)+b
$$

The transfer payment per person is restricted to be positive, so that, for example, public goods expenditure cannot be financed from a poll tax. ${ }^{6}$

Defind full income, $M$, as the net income obtained if all the individual's endowment of one unit of time is devoted to work, so that:

$$
M=w(1-t)+b
$$

The budget constraint can thus be expressed as:

$$
c+h w(1-t)=M
$$

Using the standard properties of the Cobb-Douglas utility function, the demand for private goods and leisure can be written as:

$$
\begin{gathered}
c=\left(\frac{\alpha}{\alpha+\beta}\right) M=\alpha^{\prime} M \\
h=\left(\frac{\beta}{\alpha+\beta}\right) \frac{M}{w(1-t)}=\beta^{\prime} \frac{M}{w(1-t)}
\end{gathered}
$$

Where $h<1$, that is the individual works, if the wage rate exceeds a threshold, $w_{\min }$, such that:

$$
w_{\min }=\frac{\beta^{\prime}}{1-\beta^{\prime}} \frac{b}{1-t}
$$

\footnotetext{
${ }^{6}$ Borge and Ratts $\varnothing$ (2004), in contrast, examine the finance of 'public services' using a combination of a progressive property tax and a regressive poll tax. However, they do not consider income taxes and thus do not allow for labour supply variations.
} 
Consequently, gross earnings, $y$, of workers are given by:

$$
\begin{aligned}
y & =w(1-h) \\
& =w\left(1-\beta^{\prime}\right)-\frac{b \beta^{\prime}}{(1-t)}
\end{aligned}
$$

and are a linear function of the wage rate.

\subsection{The Government Budget Constraint}

The government budget constraint requires that total revenue from the proportional income tax, equal to $t \sum_{i=1}^{n} y_{i}$ for a population of $n$ individuals, is sufficient to finance the transfer payment and the public good, $n b+G$. Hence:

$$
b+\frac{G}{n}=t \bar{y}
$$

where $\bar{y}$ denotes arithmetic mean earnings. The analysis is simplified by the assumption that $w_{i}>w_{\min }$ for all individuals, implying that everyone works: see Appendix A which discusses the relaxation of this assumption. Average income, since individuals have similar preferences, is therefore:

$$
\bar{y}=\bar{w}\left(1-\beta^{\prime}\right)-\frac{b \beta^{\prime}}{(1-t)}
$$

where $\bar{w}$ denotes the arithmetic mean wage rate. By substituting (10) in (9), it is possible to express $b$ in terms of average earnings, the tax rate and $G$, as:

$$
b=\frac{t \bar{w}\left(1-\beta^{\prime}\right)-\frac{G}{n}}{1+\beta^{\prime} \frac{t}{(1-t)}}
$$

\subsection{Indirect Utility}

The indirect utility function, $V$, is obtained by substituting the solutions for $c$ and $h$ given above into the direct utility function, so that:

$$
V=\left(\alpha^{\prime \alpha} \beta^{\prime \beta}\right)(w(1-t))^{\alpha}\left(\frac{M}{w(1-t)}\right)^{\alpha+\beta} G^{1-\alpha-\beta}
$$

Furthermore, writing:

$$
k=\alpha^{\prime \alpha} \beta^{\prime \beta}(w(1-t))^{\alpha}
$$


indirect utility becomes:

$$
V=k\left(\frac{M}{w(1-t)}\right)^{\alpha+\beta} G^{1-\alpha-\beta}
$$

Substituting (11) into (3), gives full income in terms of $G$ as:

$$
M=w(1-t)\left\{1+\left(\frac{\bar{w}}{w}\right)\left(\frac{1-t}{t}+\beta^{\prime}\right)^{-1}\left(1-\beta^{\prime}-\frac{G}{n t \bar{w}}\right)\right\}
$$

and substituting this expression into (12), $V$ can be expressed in terms of the two policy variables $t$ and $G$, the arithmetic mean wage rate in relation to the individual's wage rate, and preference parameters.

\section{Collective Choice}

This section examines policy decision regarding the composition of expenditure - the transfer payment relative to public good expenditure per person in the case where choices are based on the majority voting outcome. ${ }^{7}$ Individuals are thus assumed to have sufficient information about the government's budget constraint so that the full implications for $b$ of any policy choice of $t$ and $G$ are known.

Voting is assume to concern the level of $G$ for a given tax rate $t$, so that one dimension only is involved. ${ }^{8}$ It is well-known that a majority voting equilibrium exists, in which the median voter dominates, if all individuals have single-peaked preferences. In the present context this is guaranteed if the relationship between $V$ and $G$ is concave for all individuals, so that:

$$
\frac{\partial^{2} V}{\partial G^{2}}<0
$$

\footnotetext{
${ }^{7}$ Hence, the present approach does not allow for the types of modification to the voting model which reduce the extent to which inequality may lead to redistributive outcomes in the Romer-Roberts-Meltzer-Richard framework. These are surveyed by Harms and Zink (2003) and Borck (2007). Tridimas and Winer (2005) emphasise the role of political influence and thus the 'supply side' of government.

${ }^{8}$ Appendix C examines the case where effectively a two-stage voting procedure is used, in which individuals vote over the tax rate, knowing the outcome of a resulting vote over government expenditure on public goods.
} 
By differentiating (12) twice with respect to $G$, it is possible to show that this requirement is satisfied for all individuals. Hence the choice of $G$, for given $t$, is based on the preferences of the median voter which, in the present model, are distinguished from other voters only because of the median voter's wage rate. The median voter is therefore the individual with median wage. Letting an $m$ subscript refer to the median voter, $V_{m}$ is obtained by substitution into (12) and (13), with (15), and majority choice satisfies the first-order condition:

$$
\frac{\partial V_{m}}{\partial G_{m}}=0
$$

It can be shown that:

$\frac{\partial V_{m}}{\partial G_{m}}=k_{m}\left(\frac{M_{m}}{w_{m}(1-t)}\right)^{\alpha+\beta} G_{m}^{-(\alpha+\beta)}\left\{(1-\alpha-\beta)-\frac{G_{m}}{n} \frac{(\alpha+\beta) M_{m}^{-1}}{\left(1+\beta^{\prime} \frac{t}{1-t}\right)}\right\}=0$

Hence the term in curly brackets in (18) must be zero and, substituting for $M_{m}$ gives:

$$
\frac{G_{m}}{n} \frac{(\alpha+\beta)}{\left(1+\beta^{\prime} \frac{t}{1-t}\right)}\left(w_{m}(1-t)+\frac{t \bar{w}\left(1-\beta^{\prime}\right)-\frac{G_{m}}{n}}{\left(1+\beta^{\prime} \frac{t}{1-t}\right)}\right)^{-1}=(1-\alpha-\beta)
$$

which, after some manipulation, can be solved to give $G_{m} / n$ as:

$$
\frac{G_{m}}{n}=(1-\alpha-\beta)\left\{w_{m}+t\left(1-\beta^{\prime}\right)\left(\bar{w}-w_{m}\right)\right\}
$$

and the resulting value of $b_{m}$ is given by appropriate substitution into (11). These values apply for positive values of the social transfer, so the given tax rate must exceed the value, $t_{\min }$, where: ${ }^{9}$

$$
t_{\min }=\left(\frac{1}{1-\beta^{\prime}}\right)\left[1+\left(\frac{\bar{w}}{w_{m}}\right)\left(\frac{\alpha+\beta}{1-(\alpha+\beta)}\right)\right]^{-1}
$$

Even for a symmetric distribution of wage rates, it can be shown that $b_{m}>0$ if $t>(1-\alpha-\beta)(\alpha+\beta) / \alpha$. Hence, with sufficient revenue the median

\footnotetext{
${ }^{9}$ In addition, the tax rate is also subject to an upper limit, given the assumption that all individuals work, so that for sensible values the social transfer must remain sufficiently below the minimum wage.
} 
voter would prefer some redistributive transfer payments in addition to the tax financed public good.

The focus here is on the ratio of the transfer payment to the expenditure on the public good per person, rather than absolute values. It can be shown that this ratio, $R=b_{m} /\left(G_{m} / n\right)$, is given by:

$$
R=\frac{1-t}{1-t\left(1-\beta^{\prime}\right)}\left[\left(\frac{1}{1-\alpha-\beta}\right)\left\{\frac{w_{m}}{\bar{w}}\left(\frac{1}{t\left(1-\beta^{\prime}\right)}-1\right)+1\right\}^{-1}-1\right]
$$

This result shows that the ratio of the transfer payment to public goods expenditure per person depends, among other things, on the ratio of median wage rate to average wage rate. In a positively skewed distribution this latter ratio is of course less than unity. In other words the composition of government expenditure is determined by the skewness of the distribution of wage rates. For example, any growth in productivity, with no change in skewness, has no direct effect on the majority choice of the composition of expenditure.

The expression in (22) is highly nonlinear in $w_{m} / \bar{w}$ and $t$. Hence, in order to obtain further insights to help produce a specification that is useful for empirical work, it is useful to examine its properties further. First, it can be shown that:

$$
\frac{\partial^{2} R}{\partial t^{2}}<0
$$

so that there is a concave relationship between $R$ and $t$. The first derivative $\partial R / \partial t$ is positive for low values of $t$ and negative for relatively higher values. This is dominated by the concave relationship between $b_{m}$ and $t$, since $\partial G_{m} / \partial t$ is positive, while $\partial^{2} G_{m} / \partial t^{2}=0$ for all relevant values of $t$. The concavity of $R$ with respect to $t$ is therefore strongly affected by the labour supply effects of taxes and transfers. The median voter, while being below the average income and thus desiring some redistribution, prefers to see expenditure on the public good increase steadily as $t$ increases, despite its decreasing marginal utility.

The above result in (22) shows that the majority choice of the composition of expenditure depends only on the ratio of median to average wage rates, 
so that the absolute levels (or units of measurement) are not relevant. ${ }^{10}$ An increasing in the ratio of the median wage to the average wage (where the former is less than the latter) implies that the positive skewness, and hence degree of inequality, of the distribution decreases. ${ }^{11}$ The relationship between decreasing inequality and the ratio of the transfer payment to public goods is:

$$
\frac{\partial R}{\partial\left(\frac{w_{m}}{w}\right)}=-\frac{t\left(1-\beta^{\prime}\right)(1-\alpha-\beta)\left(1-t\left(1-\beta^{\prime}\right)\right)}{\left(1+\frac{t \beta^{\prime}}{(1-t)}\right)\left((1-\alpha-\beta)\left(\frac{w_{m}}{w}\left(1-t\left(1-\beta^{\prime}\right)\right)+t\left(1-\beta^{\prime}\right)\right)\right)^{2}}<0
$$

This result shows that more equality reduces $R$, and higher inequality (less equality) causes government expenditure to move towards relatively larger transfer payments, compared with expenditure on public goods.

The partial derivatives $\partial(G / n) / \partial(\bar{w})$ and $\partial(b) / \partial(\bar{w})$ are both positive so that an upward shift in the distribution of wage rates unambiguously increases the majority choice of total expenditure, for a given tax rate. An increase in the average wage rate, with an unchanged median, clearly reduces $w_{m} / \bar{w}$ and therefore increases inequality, leading to an increase in relative and absolute expenditure on the transfer payment, while also increasing expenditure on the public good.

The partial derivatives $\partial(G / n) / \partial\left(w_{m}\right)$ and $\partial(b) / \partial\left(w_{m}\right)$ are positive and negative respectively. Hence a increase in the median wage rate (with an unchanged arithmetic mean wage) has a positive effect on public goods and total expenditure, but reduces the absolute social transfer and the ratio of the transfer to public good expenditure. The latter can be seen from (24) and the fact than an increasing median reduces inequality.

\footnotetext{
${ }^{10}$ However, the absolute values are clearly affected by shifts in the distribution of wage rates.

${ }^{11}$ Strictly inequality and skewness refer to different concepts. However, in the context of positively skewed distributions, they are closely related: for example in lognormal distribuions, both depend only on the variance of logarithms. It is standard in the literature on voting models to refer to the ratio of median to mean income in terms of inequality.
} 


\section{Voters Care About Inequality}

This section considers how majority voting outcomes may change when individuals care about the inequality of net income. To simplify the analysis it is assumed that individual labour supply and consumption decisions continue to be made selfishly according to the maximization of $U=c^{a} h^{\beta} G^{1-\alpha-\beta}$ as above. This means that the expressions for optimal values of $c$ and $h$, along with the form of the government budget constraint, are unchanged. However, equality matters when individuals vote over the level of public good expenditure. ${ }^{12}$ Suppose the indirect utility function is augmented by an additive term containing the coefficient of variation of net income. For instance, the preferences of individuals can be defined as follows: ${ }^{13}$

$$
V_{i}=k_{i}\left(\frac{M_{i}}{w_{i}(1-t)}\right)^{\alpha+\beta} G^{1-\alpha-\beta}-\lambda\left(1+\eta_{z}\right)^{\xi}
$$

where $\eta_{z}$ is the coefficient variation of net income. In this form of indirect utility function, $\lambda$ and $\xi$ reflect the aversion to inequality. When $\lambda$ is zero, individuals do not care about inequality of net income when they vote.

Net income of individual type $i$ is $(1-t) y_{i}+b$ and substituting for $y_{i}$ from (8) gives:

$$
z_{i}=\left(1-\beta^{\prime}\right)\left(w_{i}(1-t)+b\right)
$$

Arithmetic mean net income is therefore $\bar{z}=\left(1-\beta^{\prime}\right)(\bar{w}(1-t)+b)$. The variance of net income, $\sigma_{z}^{2}$, is:

$$
\begin{aligned}
\sigma_{z}^{2}= & E\left(z_{i}-\bar{z}\right)^{2} \\
= & \left(1-\beta^{\prime}\right)^{2}(1-t)^{2} E\left(w_{i}-\bar{w}\right)^{2} \\
& \left(1-\beta^{\prime}\right)^{2}(1-t)^{2} \sigma_{w}^{2}
\end{aligned}
$$

\footnotetext{
${ }^{12}$ This implies, for example, that high wage individuals do not moderate their labour supply in order to reduce earnings inequality, but vote for some redistribution through the tax system. This type of assumption is also made by Galasso (2003), although in his approach individuals have a 'self centred' inequality aversion in that they are concerned with their own position relative to some reference group. A self-centred approach is also explored by Tyran and Sausgruber (2006).

${ }^{13}$ Other form of indirect utility function, such as $V_{i}=k_{i}\left(\frac{M_{i}}{w_{i}(1-t)}\right)^{\alpha+\beta} G^{1-\alpha-\beta}-\lambda \eta_{z} \xi$, give very similar results to those reported here.
} 
where $\sigma_{w}^{2}$ is the variance of the wage rate distribution. The coefficient of variation of net income is therefore expressed as:

$$
\eta_{z}=\frac{\sigma_{z}}{\bar{z}}=\frac{\left(1-\beta^{\prime}\right)(1-t) \sigma_{w}}{\left(1-\beta^{\prime}\right)(\bar{w}(1-t)+b)}=\eta_{w}\left\{1+\frac{b}{\bar{w}(1-t)}\right\}^{-1}
$$

where $\eta_{w}=\sigma_{w} / \bar{w}$ is the coefficient variation of wages.

As in the case where $\lambda=0$, individuals are assumed to vote on the level of public good expenditure, with a fixed tax rate, where the transfer payment is determined by the government's budget constraint. Therefore, the policy space is unidimensional. Concavity of the indirect utility function again guarantees the single-peakedness of preferences over $G$. The second derivative of $V$ is given by.

$$
\begin{aligned}
& \frac{d^{2} V_{i}}{d G^{2}}=\frac{d^{2}\left(k_{i}\left(\frac{M_{i}}{w_{i}(1-t)}\right)^{\alpha+\beta} G^{1-\alpha-\beta}\right)}{d G^{2}}- \\
& \frac{d}{d G}\left(\frac{\lambda \xi \eta_{w}\left(1+\eta_{w}\left(1+\frac{b}{\bar{w}(1-t)}\right)^{-1}\right)^{\xi-1}\left(1+\frac{b}{\bar{w}(1-t)}\right)^{-2}}{\bar{w}(1-t) n\left(1+\beta^{\prime}\left(\frac{t}{1-t}\right)\right)}\right)
\end{aligned}
$$

The first term is negative while the second term is positive, so that $\frac{d^{2} V_{i}}{d G^{2}}$ is unequivocally negative and the relationship between $V$ and $G$ is concave. Consequently, all voters have single peak preferences over $G$ and the median voter is decisive. Hence, setting $d V_{m} / d G=0$ gives the majority voting equilibrium $G$, and:

$$
\begin{aligned}
\frac{d V_{m}}{d G_{m}}= & k_{m}\left(\frac{M_{m}}{w_{m}(1-t)}\right)^{\alpha+\beta} G_{m}^{-(\alpha+\beta)}\left((1-\alpha-\beta)-\frac{G_{m}(\alpha+\beta)}{n M_{m}\left(1+\beta^{\prime} \frac{t}{1-t}\right)}\right) \\
& -\frac{\lambda \xi \eta_{w}\left(1+\eta_{w}\left(1+\frac{b_{m}}{\bar{w}(1-t)}\right)^{-1}\right)^{\xi-1}\left(1+\frac{b_{m}}{\bar{w}(1-t)}\right)^{-2}}{\bar{w}(1-t) n\left(1+\beta^{\prime}\left(\frac{t}{1-t}\right)\right)}=0
\end{aligned}
$$

Rearrangement of this expression gives:

$$
\Phi=(1-\alpha-\beta)-\Psi
$$


where:

$$
\begin{gathered}
\Phi=\frac{G_{m}}{n} \frac{(\alpha+\beta)}{\left(1+\beta^{\prime} \frac{t}{1-t}\right)}\left(w_{m}(1-t)+\frac{t \bar{w}\left(1-\beta^{\prime}\right)-\frac{G_{m}}{n}}{\left(1+\beta^{\prime} \frac{t}{1-t}\right)}\right)^{-1} \\
\Psi=\frac{\lambda \xi \eta_{w}\left(1+\eta_{w}\left(1+\frac{b}{\bar{w}(1-t)}\right)^{-1}\right)^{\xi-1}\left(1+\frac{b}{\bar{w}(1-t)}\right)^{-2} G_{m}^{(\alpha+\beta)}}{\bar{w}(1-t) n\left(1+\beta^{\prime}\left(\frac{t}{1-t}\right)\right) k_{m}\left(\frac{M_{m}}{w_{m}(1-t)}\right)^{\alpha+\beta}}
\end{gathered}
$$

Equation (31) cannot be solved explicitly for $G_{m}$. However, some insight into this can be obtained by recognising that $\Phi$ is same as the left hand side of equation (19) above, when $\lambda=0$, and is an increasing convex function of $G$. In addition, $(1-\alpha-\beta)-\Psi$ is decreasing in $G$. The profiles of $\Phi$ and $(1-\alpha-\beta)-\Psi$ are shown in Figure (1). The voting equilibrium for $\lambda=0$ is at point $\mathrm{A}$ in the figure, and for $\lambda \neq 0$ it is at point B. Clearly a concern for inequality reduces the majority choice of $G$ and increases the transfer payment, $b$, for a fixed $t$. In view of the nonlinearity of the first-order condition, it is useful to consider numerical examples of the variations in $G_{m}$. These are reported in the following section.

\section{Some Numerical Examples}

This section provides numerical examples of the sensitivity of majority voting outcomes to variations in selected parameters of the model, in particular the tax rate, $t$, and the ratio of the median wage to the arithmetic mean wage, $w_{m} / \bar{w}$. In addition to illustrating characteristics of the framework which are not immediately obvious, it helps to motivate the specification used for empirical work in section 6 below.

The benchmark parameters are shown in Table 1 . The preference parameters of $\alpha=0.58$ and $\beta=0.4$ are chosen so that, with the benchmark tax rate of $t=0.25$, the proportion of time devoted to labour supply is sensible. The arithmetic mean and median wage rate, expressed in annual terms, are $\$ 70000$ and $\$ 60000$ respectively. ${ }^{14}$

\footnotetext{
${ }^{14}$ These are consistent with a lognormal distribution with mean and standard deviation
} 
Figure 1: Equilibrium With and Without Inequality Aversion

Figure 2 shows indirect utility for variations in $G$, for a wide range of wage rates, illustrating the concave and single-peaked nature of preferences over $G$.

Table 1: Benchmark Parameter Values

\begin{tabular}{cc}
\hline Parameter & Value \\
\hline$\alpha$ & 0.58 \\
$\beta$ & 0.4 \\
$t$ & 0.25 \\
$\bar{w}$ & 70000 \\
$w_{l}$ & 7350 \\
$n$ & $20 \times 10^{6}$ \\
\hline
\end{tabular}

of logarithms of hourly wage rates of 2.87 and 0.56 : these are similar to those for Australia. Using the properties of the lognormal distribution the arithmetic mean and the median hourly wage rate are $20.64=\exp (2.87+0.56 / 2)$ and $17.64=\exp (2.87)$ : see Aitchison and Brown (1957). Furthermore, the maximum hours per day are set at 13 to obtain annual equivalents. 


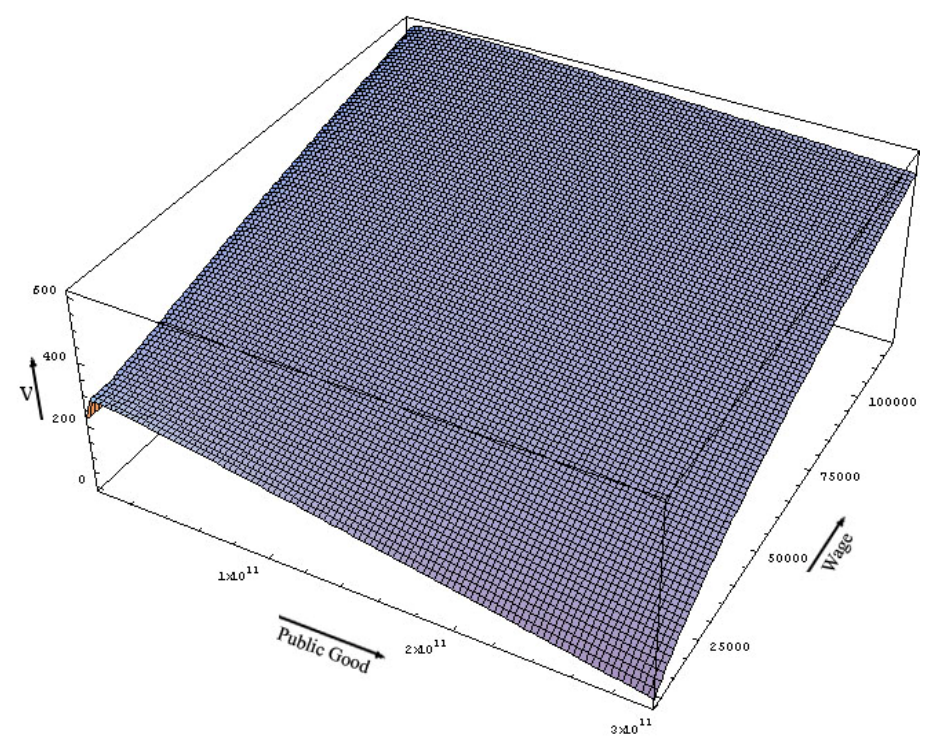

Figure 2: Indirect Utility Function

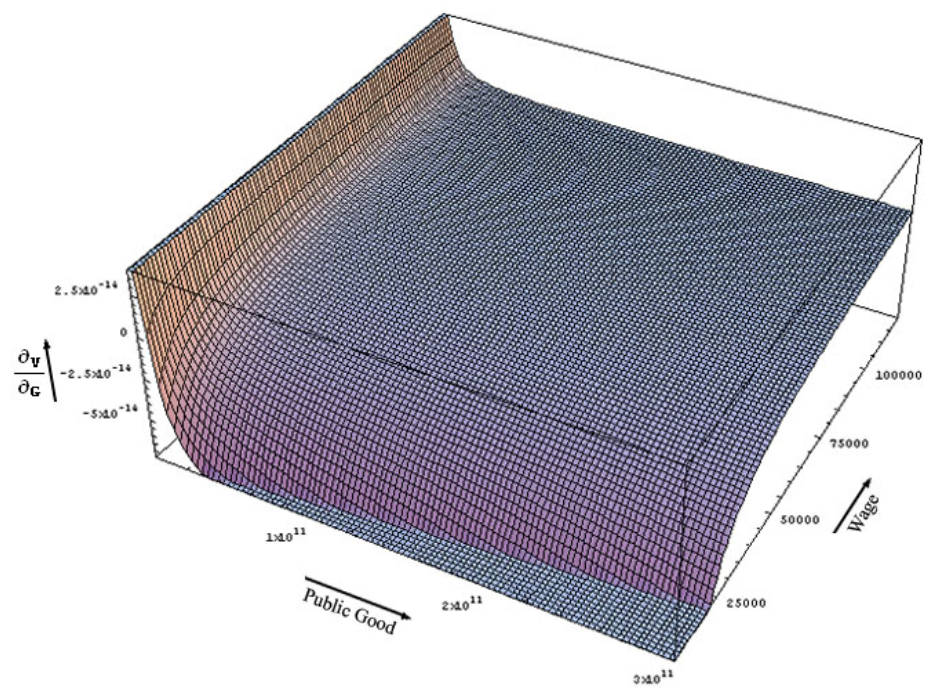

Figure 3: First Derivative of Indirect Utility Function wrt $G$ 


\subsection{No Inequality Aversion}

Consider first the basic framework where voters do not care about inequality. Figure 3 shows the first derivative of indirect utility with respect to $G$. Figure 4 shows the relationship between $b_{m} /\left(G_{m} / n\right)$ and $w_{m} / \bar{w}$ and, for the other benchmark values. It illustrates the fact that the majority choice of $b_{m} /\left(G_{m} / n\right)$ falls at a decreasing rate as inequality falls, that is as $w_{m} / \bar{w}$ increases towards unity.

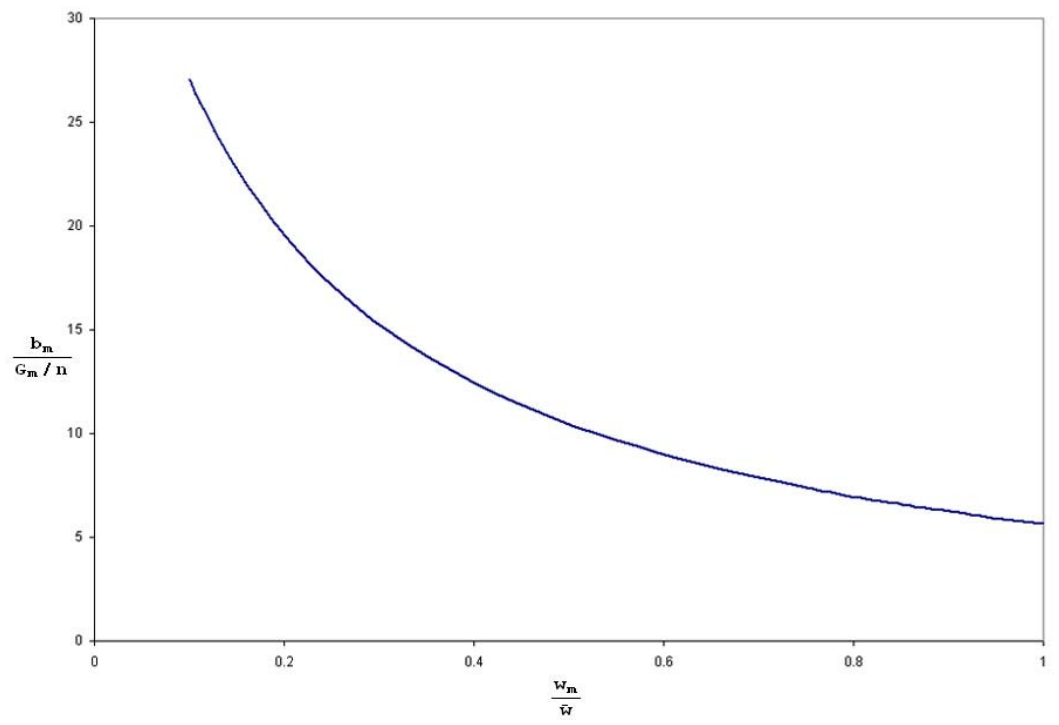

Figure 4: Variation in $b_{m} /\left(G_{m} / n\right)$ with $w_{m} / \bar{w}$

Figure 5 shows the variation in different types of government expenditure as the tax rate (considered here to be exogenous) increases. As shown in the individual figures there is an inverted U-shaped relationship between tax rate and transfer payment, total expenditure as well as $b_{m} /\left(G_{m} / n\right)$. Nevertheless, expenditure on public goods is linearly related to the tax rate: this was established analytically above, where it was shown that $\partial G_{m} / \partial t$ is positive and $\partial^{2} G_{m} / \partial t^{2}=0$. 


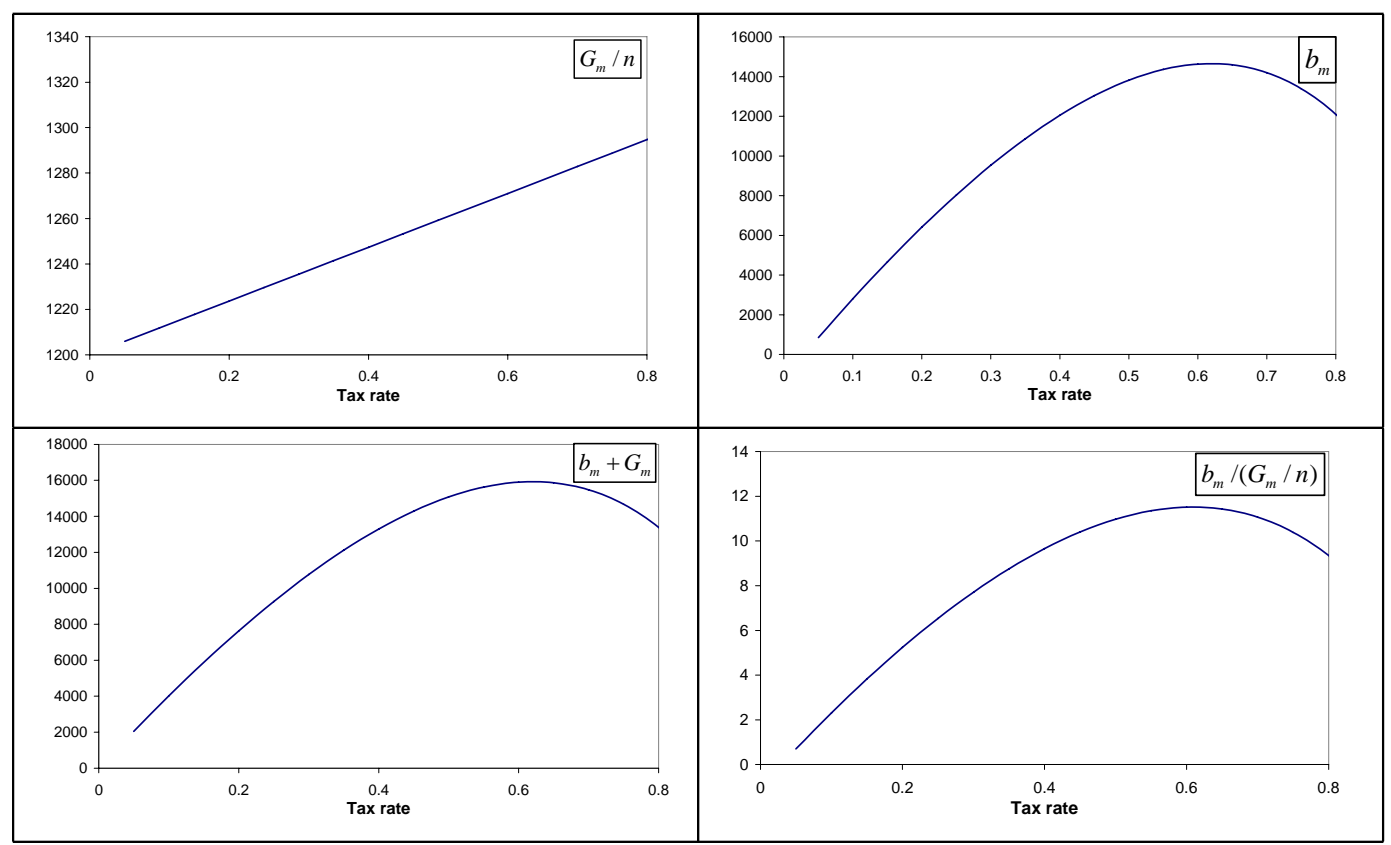

Figure 5: Change in Tax Rate and Voting Equilibrium

\subsection{Inequality Aversion}

Figure 6 shows the relationship between the coefficient variation of net income and expenditure per capita on public goods, for the benchmark tax rate and other parameters. ${ }^{15}$ As $G_{m} / n$ increases, the amount available for the transfer payment falls so that the tax and transfer system is less redistributive. However, over the wide range of $G_{m} / n$ examined, there is little variation in $\eta_{z}$.

Although an analytical result is not available for the case where individuals, when voting, care about inequality, numerical methods can be used to solve the nonlinear equation for the majority voting outcome. Figures 7 and 8 show the median voter's choice of expenditure on public goods and the transfer payment, for alternative values of $\eta$ and $\xi$.

As expected, raising the degree of inequality aversion reduces the majority choice of the share of public good expenditure; however the reduction is quite small over a wide range of $\xi$, except for the highest values of $\lambda$. In the model,

\footnotetext{
${ }^{15}$ The range of values here are realistic: for example, the coefficient variation of wage rates for Australia is approximately 0.2 .
} 


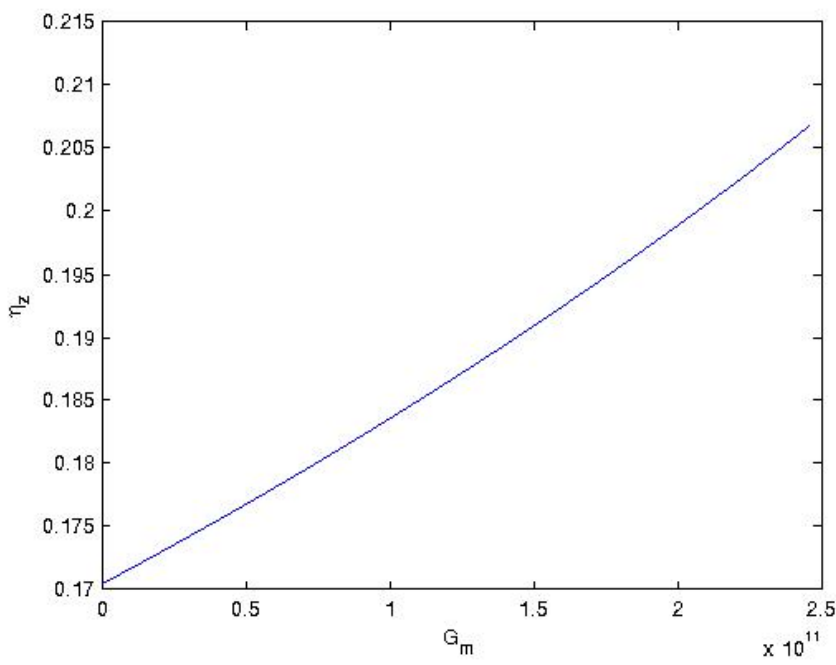

Figure 6: Coefficient of Variation of Net Income

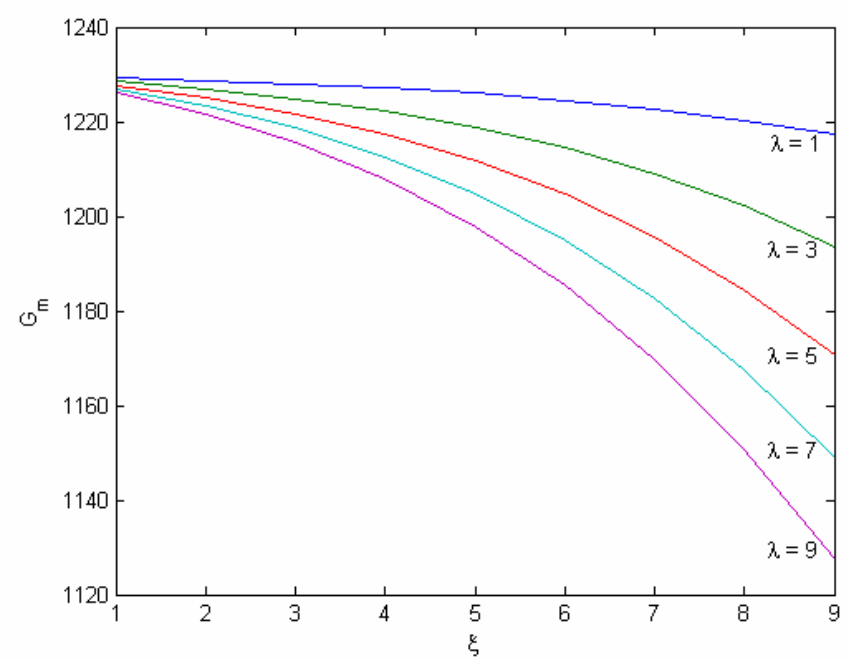

Figure 7: Inequality aversion and Choice of $G_{m}$ 


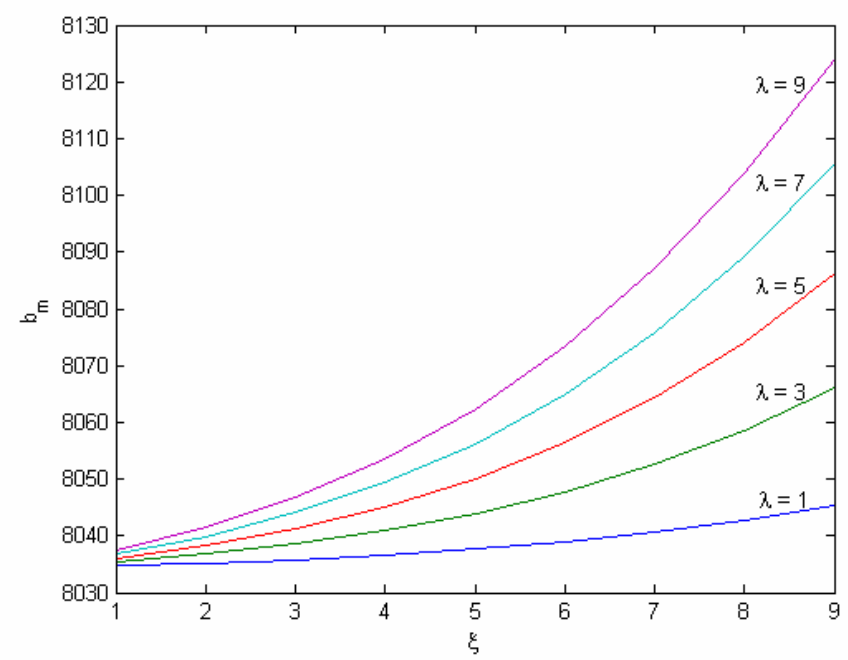

Figure 8: Inequality Aversion and Choice of Basic Income

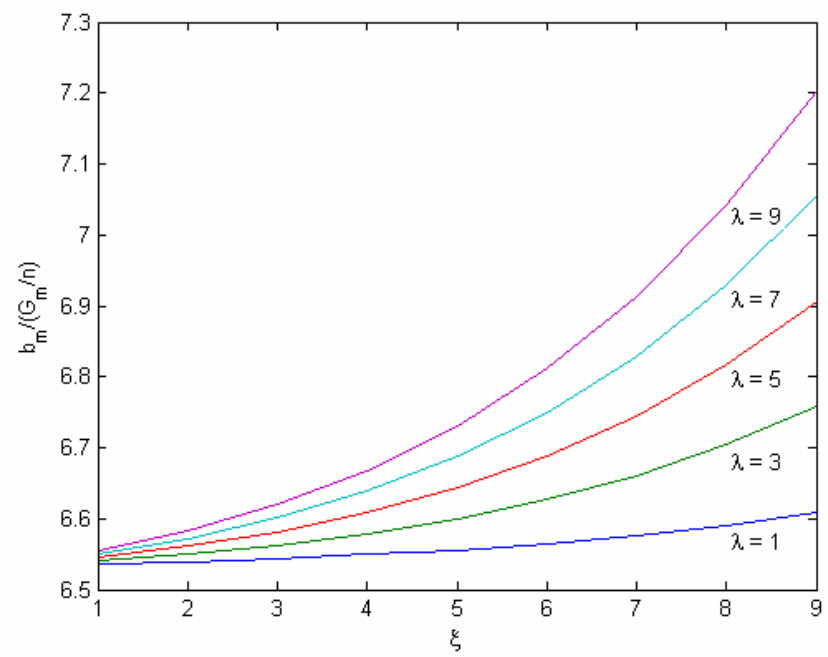

Figure 9: Majority Choice of Composition of Expenditure 
labour supply incentive effects impose a strong constraint on the ability to redistribute income (that is, to raise $b$ for a given tax rate, by reducing $G$ ). Furthermore, the public good enters the utility function directly, so for the median voter there is a clear cost of reducing inequality which cannot be shifted to higher income earners (and hence higher taxpayers).

\section{Data and Empirical Results}

This section uses cross-sectional data for a sample of democracies to investigate the variation in the composition of expenditure, the ratio of transfer payments to public good expenditure per capita. A major problem is raised by the data requirements as it is possible only to obtain approximations to the variables needed. The construction of the sample is described in subsection 6.1. The regression results are reported in subsection 6.2.

\subsection{The Data}

The first question regarding the data concerns the countries to be included in the analysis. The Polity IV (2004) dataset provides, for each country, an index of democracy. This index varies between 0 and 10, the latter representing the highest level of democracy. It was decided to include those countries with an index from 9 to 10 since the year 2000. These include parliamentary, presidential or semi-presidential countries. The resulting 29 democratic countries are: Australia, Austria, Belgium, Canada, Costa Rica, Cyprus, Czech Republic, Denmark, Finland, France, Germany, Greece, Hungary, Ireland, Israel, Italy, Jamaica, Lithuania, Mauritius, Netherlands, Norway, Portugal, Slovenia, Spain, Sweden, Switzerland, United Kingdom, United States and Uruguay.

The model examined above is one in which voting on the level of expenditure on public goods, for a given tax rate, which results, via the budget constraint, in a ratio of the transfer payment to public good expenditure per person. In practice there is not always a clear distinction between pure public and private goods. Using the Government Finance Statistics Yearbook (2000-2006), public good expenditure was obtained as the sum of expendi- 
ture by governments on the following categories: defence, public order and safety, economic affairs, environmental protection, health, education and social protection. However, part of expenditure on education and health clearly consists of publicly provided private goods rather than pure public goods. The results reported below are for the case where one third of expenditure on education and health is considered to be expenditure on public goods. Experiments were carried out using different proportions but these had little effect on the results.

A difficulty also arises with the measurement of transfer payments. These are modelled above as a basic income, but in practice countries vary in the type of transfer payment system in operation. In the following empirical analysis, transfers are measured as including: all unrequited non repayable transfers on current account to private and public enterprises. Grants to foreign governments, international organizations, and other government units are excluded. Again the data are taken from the Government Finance Statistics Yearbook (2000-2006).

Governments in this model finance the expenditure by income tax revenue. In practice several taxes are used, with varying marginal rates. The tax rate variable was constructed as the ratio of tax revenue to GDP. The source for data on tax revenue and GDP are Government Finance Statistics Yearbook (2000-2006) and WDI (2006) respectively. Tax revenue refers to compulsory transfers to the central government for public purposes. It contains taxes and social contributions. The group of taxes includes: tax on income, profit, capital gain; payroll and workforce; properties; good and services; international trade and transactions and 'other taxes'.

A central variable in the model is the ratio of the median wage to the average wage rate, $w_{m} / \bar{w}$. Unfortunately it is not possible to obtain data on wage rate distributions for the different countries. It is necessary to use a proxy, equal to the ratio of median to average income: Appendix B examines the relationship between this ratio for wage and earnings distributions, suggesting that the latter can be a reasonable approximation for the ratio of median to mean wage. Information on the distribution of income for the countries in the sample was obtained from the WDI (2006) and World In- 
come Inequality Database (2007). ${ }^{16}$ Unfortunately the income concept varies between countries. In some cases it is gross income while in others it is a net income measure. This means that it was not possible to include in the following regression analyses a separate variable for the inequality of net income. However, the previous analysis has found that any independent effect of an aversion to inequality is likely to be small. Furthermore, the unit of analysis varies between the individual and the household.

This information is in the form of the Gini index, so that a transformation between the Gini measure and the required ratio must be used. Suppose incomes follow the lognormal distribution with mean and variance of logarithms of $\mu$ and $\sigma^{2}$ respectively. Hence the median and mean income are $e^{\mu}$ and $e^{\mu+\sigma^{2} / 2}$ respectively and the proxy for $w_{m} / \bar{w}$ is thus: ${ }^{17}$

$$
\frac{e^{\mu}}{e^{\mu+\sigma^{2} / 2}}=e^{-\frac{\sigma^{2}}{2}}
$$

Equation (34) shows that ratio of median to mean income for each country depends only on the variance of logarithms of income. The latter can be obtained from the Gini coefficient, $G$, using the lognormal property that:

$$
G=2 N\left(\frac{\sigma}{\sqrt{2}}\right)-1
$$

Where $N(\sigma / \sqrt{2})$ is the area contained by a standard normal distribution below $\sigma / \sqrt{2}$. Hence:

$$
\sigma=\sqrt{2} N^{-1}\left(\frac{G+1}{2}\right)
$$

where $N^{-1}$ is the inverse function. The general form of the relationship between the ratio of median to mean and the Gini measure is shown in Figure 10.

For most countries, the Gini index is available only for selected years. Hence, the average, from available data between 2000 and 2005, was used to calculate the ratio of median to mean wage. Similarly, averages of government expenditures and revenue over the same period were used.

\footnotetext{
${ }^{16}$ The latter database was used to obtain data for Australia, Czech Republic, Denmark, France, Mauritius, the Netherlands, Portugal, Slovenia and the United Kingdom.

${ }^{17}$ The assumption of lognormality must be regarded as a convenient approximation rather than an accurate description. For example, the two-parameter form implies that Lorenz curves do not intersect, whereas this is known to arise in practice.
} 


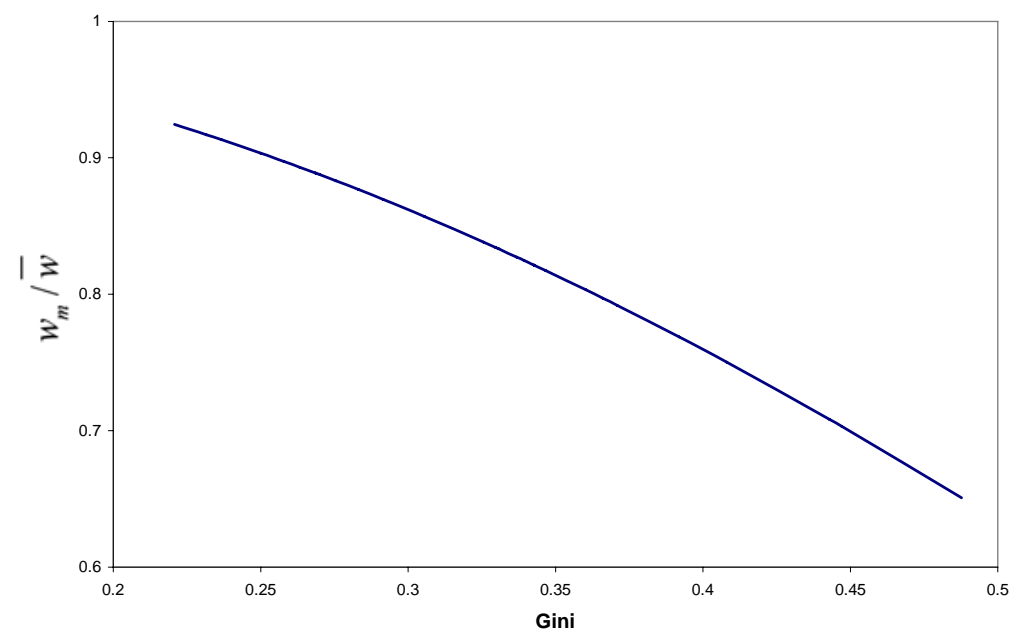

Figure 10: Ratio of Median to Mean Wage Rate and Gini Coefficient

Table 2: Averages of Variables for Different Country Groups

\begin{tabular}{lccc}
\hline Group & $b /(G / n)$ & $w_{m} / \bar{w}$ & $t$ \\
\hline Developed & 0.62 & 0.85 & 0.39 \\
Developing & 0.71 & 0.78 & 0.28 \\
Non-Former Communist & 0.63 & 0.82 & 0.36 \\
Former Communist & 0.70 & 0.89 & 0.37 \\
Non-Scandinavian & 0.65 & 0.82 & 0.35 \\
Scandinavian & 0.57 & 0.90 & 0.45 \\
\hline
\end{tabular}


The countries listed above can be divided into various groups. First, developing economies include Costa Rica, Czech Republic, Hungary, Jamaica, Lithuania, Mauritius and Uruguay. They belong to the group of middleincome economies in the World development Indicator (WDI) classification which contains countries in which GNI per capita in 2005 was between $\$ 876$ and $\$ 10,725$. Second, there are the Scandinavian countries, including Denmark, Finland, Norway and Sweden, and former communist countries which include Czech Republic, (East) Germany, Hungary, Lithuania and Slovenia. Table 2 presents arithmetic mean values of proxies used to measure the ratio of benefits to public good expenditure per person, the ratio of the median to the arithmetic mean wage rate, and the tax rate. These differences and the different characteristics of those countries suggest that, in the regression analysis, it may useful to introduce dummy variables. ${ }^{18}$

\subsection{Regression Results}

Despite the highly nonlinear nature of the expression for $R=b /(G / n)$ in equation (22), the numerical examples suggest that it is appropriate to regress measures of $R$ on the proxies for $w_{m} / \bar{w}$ and $t$ and their squares. Other systematic differences between groups of democratic countries further suggest the potential value of dummy variables.

The regression results are reported in Table $3 .{ }^{19}$ A quadratic relationship between $R=b /(G / n)$ and $w_{m} / \bar{w}$ is obtained, but importantly the above analysis suggests that $\partial R / \partial\left(w_{m} / \bar{w}\right)$ should be negative for all values of $\left(w_{m} / \bar{w}\right)$ below 1 . This is confirmed by the (unconstrained) results, since $\partial R / \partial\left(w_{m} / \bar{w}\right)=-28.71+2(17.27)\left(w_{m} / \bar{w}\right)$. Hence it can be concluded that a reduction in inequality, that is an increase in $\left(w_{m} / \bar{w}\right)$ towards 1 , is associated with a reduction in the transfer payment relative to public good

\footnotetext{
${ }^{18}$ It would be useful to examine the specification using a sample of non-democratic countries. This is not possible because of data limitations. However, from Government Finance Statistics (2000-2006) comparable information on $b /(G / n)$ for Bahrain, Bhutan, China, Jordan, Kuwait and Oman were obtained. The average ratio was found to be 0.178 , which is significantly lower that for the countries shown in Table 2.

${ }^{19}$ In order to allow for heteroskedasticity, the data were weighted by the reciprocal of the square of $w_{m} / \bar{w}$. However, this was found to have little effect on the results.
} 
expenditure. But $R$ falls at a decreasing rate: as the median approaches the arithmetic mean, further reductions in inequality have a relatively small effect on the composition of expenditure.

This empirical finding, that a more redistributive policy (higher transfer expenditure relative to public goods) is preferred by a majority of taxpayers when inequality is higher, may be compared with the majority of studies which find - based on a model of voting over a linear tax - that higher redistributive taxation is not consistently associated with higher inequality. ${ }^{20}$ The present approach instead takes the size of government, the tax rate, as given and examines the resulting composition of expenditure.

Table 3: Regression Results: Dependent variable: $b /(G / n)$

\begin{tabular}{lrc}
\hline Variables & Coeff & $t$-value \\
\hline$w_{m} / \bar{w}$ & -28.71 & -1.58 \\
$\left(w_{m} / \bar{w}\right)^{2}$ & 17.27 & 1.50 \\
Tax rate & 14.29 & 2.18 \\
Tax rate ${ }^{2}$ & -15.47 & -1.69 \\
Developing & 0.61 & 2.67 \\
Former communist & -0.38 & -1.57 \\
Scandinavian & -0.29 & -1.19 \\
Constant & 9.44 & 1.31 \\
\hline$R^{2}$ & 0.48 & \\
\hline
\end{tabular}

The results also show a quadratic profile of $R$ with respect to $t$. However, for consistency with expections based on the model examined above, this profile should reach a maximum at a value of $t$ well before $t=1$. This property is also confirmed. Transfer payments increase relative to public good expenditure for tax increases in the lower range of tax rates and fall for increases in the higher tax ranges. It can be seen that $\partial R / \partial t=14.29-$ $2(15.47) t$ so that the turning point occurs at a tax rate of $t=0.46$. Transfer payments are reduced relative to public good expenditure as a result of the negative incentive effects of further increases in the tax rate over the higher ranges.

\footnotetext{
${ }^{20}$ See the survey by Borck (2007).
} 


\section{Conclusions}

This paper has considered whether the ratio of transfer payments to expenditure on public goods in democracies can be explained as the outcome of majority voting. A simple model was constructed in which individuals with similar preferences, but differing abilities and thus wages, vote for government expenditure on a public good, for a given tax rate in a proportional income tax. Hence voting is over only one dimension and a majority voting equilibrium is shown to exist. The resulting level of a transfer payment, in the form of a basic income, is given by the government's budget constraint. Comparisons were made between the case where voters act entirely selfishly and where they have an aversion to net income inequality, although their private consumption and labour supply decisions are assumed to be made independently of the income distribution.

In the case where voters do not care about the income distribution, an explicit closed-form solution was found for the ratio of transfers to public good expenditure per person, expressed in terms of the ratio of the median to the arithmetic mean wage and the given tax rate. In view of the nonlinearity of this relationship, and the difficulty of obtaining a solution when inequality aversion is relevant, numerical examples were presented to illustrate the basic properties of the models.

The numerical results provided useful insights into the various relationships involved, suggesting that the ratio of transfers to public goods expenditure per person can be expressed as a quadratic function both of the ratio of the median to the mean wage, and of the tax rate. Data for 29 democratic countries were used to estimate a cross-sectional regression, which also included dummy variables to allow for systematic differences between various groups of countries. Data limitations meant that it was not possible to test for a possible role for inequality aversion, although the numerical results displayed relatively little sensitivity. The empirical results confirmed a priori expectations. In particular, reductions in the skewness of the wage rate distribution (an increase in the ratio of the median wage to the arithmetic mean wage) were found to be associated with reductions in transfer payments rela- 
tive to public goods expenditure, at a decreasing rate. Furthermore, increases in the tax rate, from relatively low levels, are associated with increases in the relative importance of transfer payments. But beyond a certain level, further tax rate increases are associated with a lower ratio of transfers to public goods. The results tentatively support the potential applicability of a majority voting framework to the determination of the composition of government expenditure, compared with the determination of the absolute size of government as reflected in the aggregate tax rate. 


\section{Appendix A: Budget Constraint with Some Non-workers}

The analytical results derived above were simplified by the assumption that all individuals work. This appendix considers the government budget constraint in the case where not all individuals have a wage level above the value $w_{\min }=\frac{\beta^{\prime}}{1-\beta^{\prime}} \frac{b}{1-t}$, so that some individuals do not work. In this case $y_{i}=w_{i}\left(1-\beta^{\prime}\right)-\frac{b \beta^{\prime}}{(1-t)}$ and average earnings becomes:

$$
\bar{y}=\frac{1}{n} \sum_{w>w_{\min }}\left\{w_{i}\left(1-\beta^{\prime}\right)-\theta\right\}
$$

where $\theta=b \beta^{\prime} /(1-t)$. Hence:

$$
\bar{y}=\bar{w}\left(1-\beta^{\prime}\right) H\left(w_{\min }\right)
$$

where: ${ }^{21}$

$$
H\left(w_{\min }\right)=\left\{1-F_{1}\left(w_{\min }\right)\right\}-\frac{\theta}{\left(1-\beta^{\prime}\right) \bar{w}}\left\{1-F\left(w_{\min }\right)\right\}
$$

and $F_{1}\left(w_{\min }\right)$ and $F\left(w_{\min }\right)$ denote respectively the proportion of total wage (rates) and the proportion of people with $w<w_{\min }$. These correspond to the ordinate and abscissa of the Lorenz curve of wage rates at the point where $w=w_{\min }$. Hence setting these proportions equal to zero gives the simpler result given earlier for average gross earnings.

In voting over the composition of expenditure for given $t$, the effect of having some non-workers would be to reduce the median voter's preferred ratio of the social transfer to the public good per person, in view of the greater incentive effects of higher transfer payments. However, the basic form of relationships would be unchanged.

\footnotetext{
${ }^{21}$ The role of this type of function in tax and transfer systems is examined in detail in Creedy (1996).
} 


\section{Appendix B: Earnings and Wage Rate Distri- butions}

It was mentioned above that data on wage rate distributions are not available for the countries considered, so that a proxy variable based on the ratio of median earnings to arithmetic mean earnings had to be used. This appendix examines the relationship between the two distributions. As above, let $y, w$ and $h$ denote earning, wage rate and hours of work respectively. Then:

$$
y=w h
$$

and:

$$
\log y=\log w+\log h
$$

Then if $\mu_{y}$ and $\sigma_{y}^{2}$ denote the mean and variance of logarithms of $y$, and similarly for $w$ :

$$
\sigma_{y}^{2}=\sigma_{w}^{2}+\sigma_{h}^{2}+2 \sigma_{w h}
$$

and:

$$
\mu_{y}=\mu_{w}+\mu_{h}
$$

If $w$ and $h$ lognormally distributed, then $y$ is also lognormally distributed and the median and mean are:

$$
\begin{gathered}
y_{m}=\exp \left(\mu_{w}+\mu_{h}\right) \\
\bar{y}=\exp \left(\mu_{w}+\mu_{h}+\frac{1}{2} \sigma_{y}^{2}\right)
\end{gathered}
$$

Then:

$$
\begin{aligned}
\frac{y_{m}}{\bar{y}} & =\exp \left(-\frac{1}{2} \sigma_{y}^{2}\right) \\
& =\exp \left(-\frac{1}{2}\left(\sigma_{w}^{2}+\sigma_{h}^{2}+2 \sigma_{w h}\right)\right)
\end{aligned}
$$

While:

$$
\frac{w_{m}}{\bar{w}}=\exp \left(-\frac{1}{2} \sigma_{w}^{2}\right)
$$

Hence:

$$
\frac{w_{m}}{\bar{w}}=\frac{y_{m}}{\bar{y}} \psi
$$


where:

$$
\psi=\exp \left(-\frac{1}{2} \sigma_{h}^{2}-\sigma_{w h}\right)
$$

The question of importance is how $\psi$ varies. If a regression requires the use of $\log \frac{w_{m}}{\bar{w}}$, the use of $\log \frac{y_{m}}{\bar{y}}$ instead effectively involves an omitted variable equivalent to $\frac{1}{2} \sigma_{h}^{2}+\sigma_{w h}$. The term $\sigma_{h}^{2}$ can reasonably be assumed to be small , so the question is whether the covariance $\sigma_{w h}$ is likely to vary much between countries. Unfortunately suitable data are not available.

\section{Appendix C: Choice of The Tax Rate}

The above analysis examined voting over the composition of expenditure, the ratio of the basic income to public good expenditure per capita, on the assumption that the income tax rate is given exogenously. It is also of interest to consider a form of two-stage voting procedure in which individuals vote on the income tax rate itself, on the assumption that they actually know the conditional choice of expenditure composition for any tax rate. In this case voting may be regarded as involving just one dimension, the tax rate, and the usual conditions apply under which a voting equilibrium exists. ${ }^{22}$

Under these conditions, indirect utility, as expressed in (12) as a function of $G$ and $t$, can be written in terms of $t$ by substituting for $G$ using (20). This produces a rather cumbersome expression for $V$ in terms of $t$. The indirect utility function is:

$$
V=k\left(1+\left(\frac{\bar{w}}{w}\right)\left(\frac{1-t}{t}+\beta^{\prime}\right)^{-1}\left(1-\beta^{\prime}-\frac{G}{n t \bar{w}}\right)\right)^{\alpha+\beta} G^{1-\alpha-\beta}
$$

with $G=n(1-\alpha-\beta)\left\{w+t\left(1-\beta^{\prime}\right)(\bar{w}-w)\right\}$.

The complexity of the resulting expression makes it difficult to establish the single-peakedness of preferences analytically; for example, differentiating

\footnotetext{
${ }^{22}$ In a broader framework, it would be desirable to allow the tax rate to depend also on the need to finance other forms of expenditure. Even if these do not enter utility functions and are imposed exogneously (both common assumptions), the need for a minimum rate influences labour supply. Hence it would not be appropriate simply to add a minimum rate to that discussed here. However, the general results obtained here would be expected to apply in such a broader framework.
} 
$V$ twice with respect to $t$ produces a lengthy expression which does not appear to have an unconditional sign. However, numerical analysis confirms that preferences are indeed single peaked. Figure (11) illustrates indirect utility for individuals with different wage rates. The other relevant variables are the same as the benchmark values given above. Indirect utility is clearly a concave function of $t$. Consequently, preferences over tax rate are singlepeaked and the median voter is the decisive voter. ${ }^{23}$

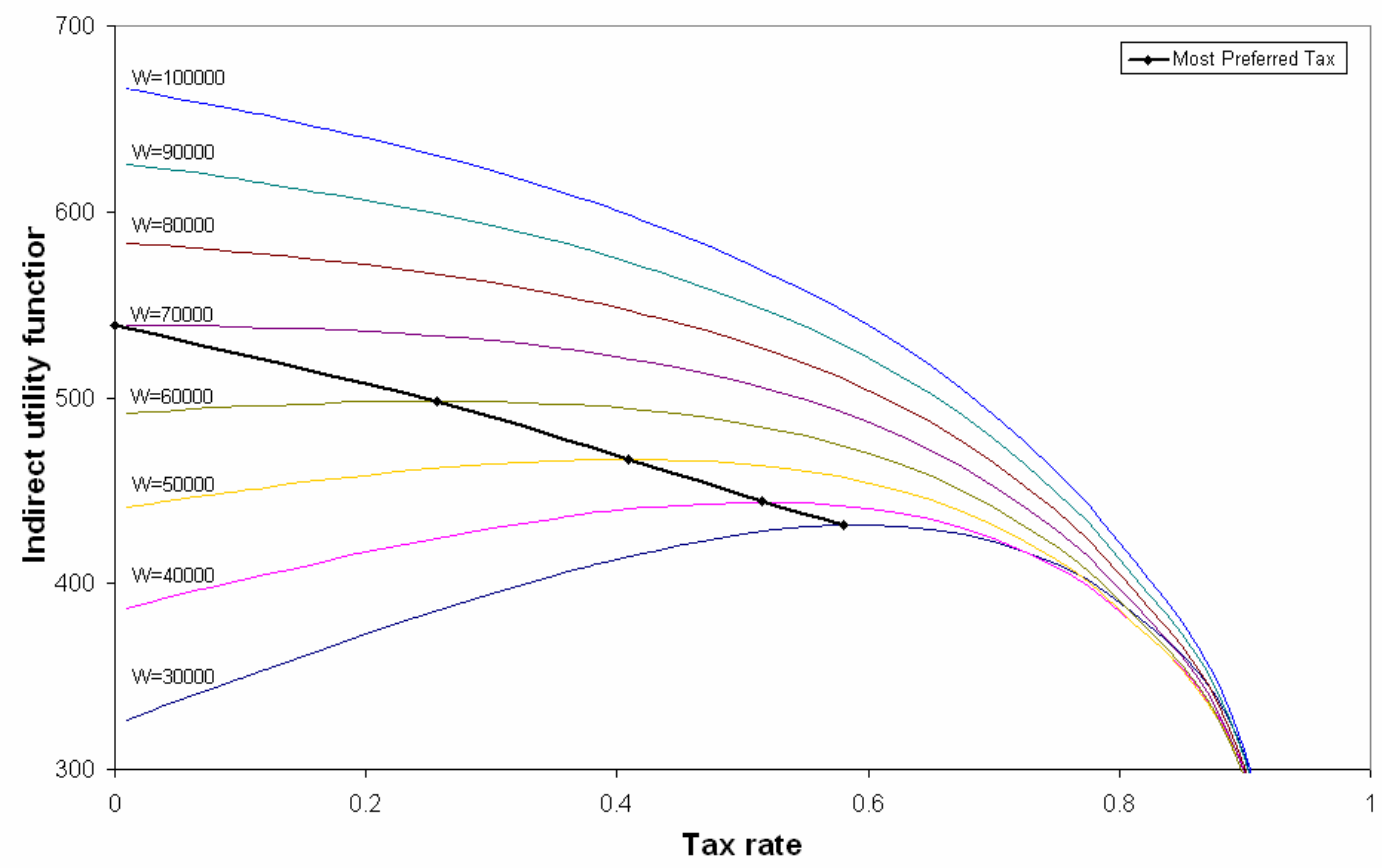

Figure 11: Indirect utility function and tax

In order to see the effect of wage inequality on median voter's choice of tax rate, the relationship between $t_{m}$ and $w_{m} / \bar{w}$ is shown in figure (12). The tax rate falls more rapidly as $w_{m} / w$ approaches 1 , or inequality falls.

These results are obtained using the simplifying assumption that all individuals are working. An implication of allowing some workers to be at the

\footnotetext{
${ }^{23}$ Those with $w$ above $\bar{w}$ prefer some expenditure on public goods, since they gain utility from it, although they have no desire for redistribution via a transfer payment. They prefer public goods to be financed using $t=0$ and a negative value of $b$; that is, they prefer a regressive poll tax.
} 


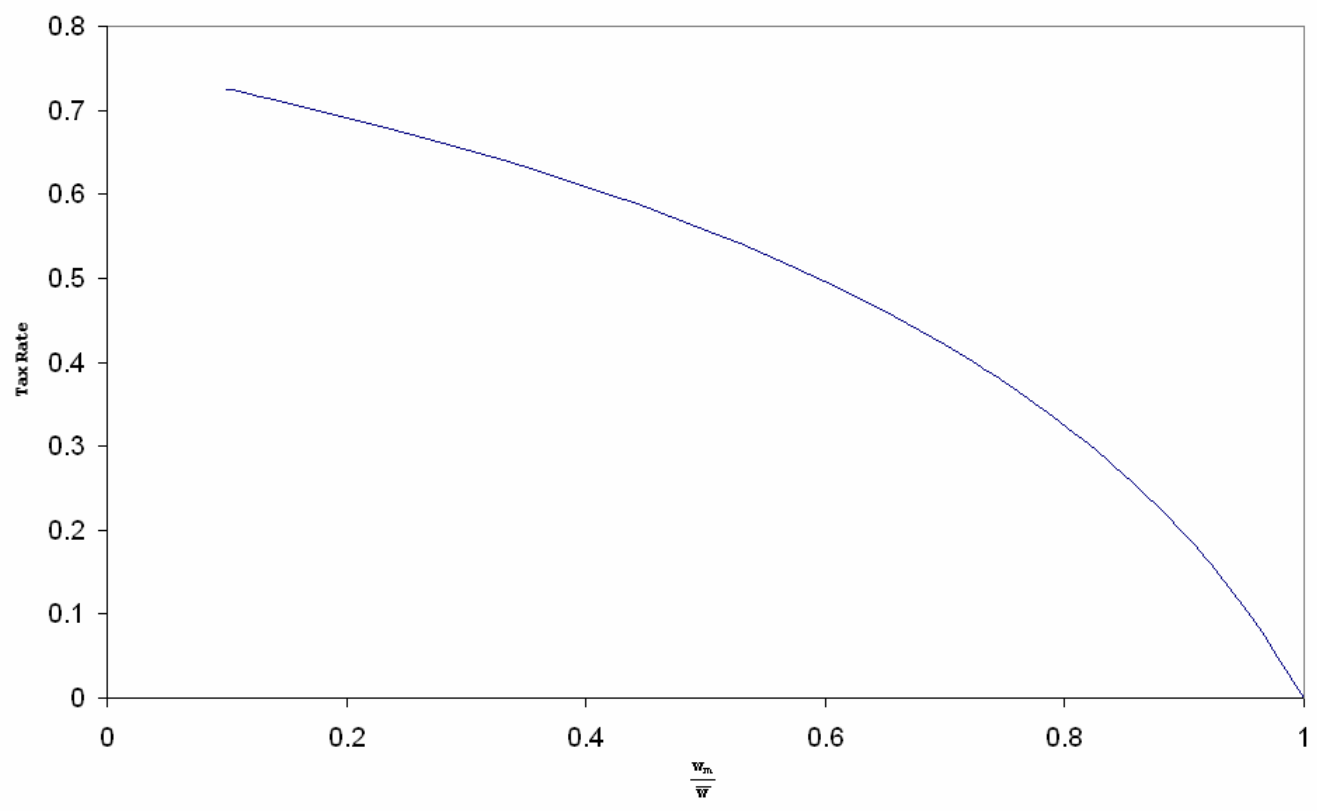

Figure 12: Tax rate and inequality

corner solution where $h=1$ has the effect that, for some workers, preferences over the tax rate are likely to be double-peaked. Thus, over a higher ranges of $t$, where individuals do not work, they would vote for higher rates, since they would benefit without having to pay taxes. This would continue until the incentive effects on remaining workers actually reduces the total revenue available. However, in majority voting over the tax rate, Roberts (1977)showed that an equilibrium exists so long as there is hierarchical adherence (that is, an unchanged ranking of individuals), a condition which applies in the present model. 


\section{References}

[1] Aitchison, J.A. and Brown, J.A.C. (1957) The Lognormal Distribution. Cambridge: Cambridge University Press.

[2] Azzimonti, M., De Francisco, E. and Krusell, P. (2006) Median-voter equilibria in the neoclassical growth model under aggregation. Scandinavian Journal of Economics, 108, pp. 587-606.

[3] Bearse, P. Glomm, G. and Janeba, E. (2001) Composition of government budget, non-single peakedness, and majority voting. Journal of Public Economic Theory, 3, pp. 471-481.

[4] Borck, R. (2007) Voting, inequality and redistribution. Journal of Economic Surveys, 21, pp. 90-109.

[5] Borge, L-E. and Ratts $\varnothing$, J. (2004) Income distribution and tax structure: empirical test of the Meltzer-Richard hypothesis. European Economic Review, 48, pp. 805-826.

[6] Creedy, J. (1996) Fiscal Policy and Social Welfare. Cheltenham: Edward Elgar.

[7] Galasso, V. (2003) Redistribution and fairness: a note. European Journal of Political Economy, 19, pp. 885-892.

[8] Government Finance Statistics Yearbook (2001-2006) Washington, D.C: International Monetary Fund.

[9] Grossmann, V. (2003) Income inequality, voting over the size of public consumption, and growth. European Journal of Political Economy, 19, pp. 265-287.

[10] Harms, P. and Zink, S. (2003) Limits to redistribution in a democracy: a survey. European Journal of Political Economy, 19, pp. 651-668

[11] Hassler, J. Krusell, P. Storesletten, K. and Zilibotti, F. (2005) The dynamics of government. Journal of Monetary Economics, 52(7), pp. 13311358. 
[12] Hassler, J. Storesletten, K. and Zilibotti, F. (2007) Democratic public good provision. Journal of Economic Theory, 133, pp. 127-151.

[13] Krusell, P. and Rios-Rull, J-V. (1999) On the size of U.S. government: political economy in the neoclassical growth model. American Economic Review, 89, pp. 1156-1181.

[14] Meltzer, A.H. and Richard, S.F. (1981) A rational theory of the size of government. Journal of Political Economy, 89, pp. 914-927.

[15] Mueller, D.C. (2003) Public Choice III. New York: Cambridge University Press.

[16] Polity IV (2004) University of Maryland, Center for International Development and Conflict Management. Available at: http://www.cidcm.umd.edu/polity/data/.

[17] Roberts, K.W.S. (1977) Voting over income tax schedules. Journal of Public Economics, 8, pp. 329-340.

[18] Romer, T. (1975) Individual welfare, majority voting and the properties of a linear income tax. Journal of Public Economics, 4, pp. 163-185.

[19] Tabellini, G. and Alesina, A. (1990) Voting on the budget deficit. American Economic Review, 80, pp. 37-49.

[20] Tridimas, G. and Winer, S. L. (2005) The political economy of government size. European Journal of Political Economy, 21, pp. 643-666.

[21] Tuomala, M. (1985) Simplified formulae for optimal linear income tax. Scandinavian Journal of Economics, 87, pp. 668-672.

[22] Tyran, J-R. and Sausgruber, R. (2006) A little fairness may induce a lot of redistribution in democracy. European Economic Review, 50, pp. 469-485.

[23] World Development Indicator (WDI) (2007) Washington: World Bank. Available at: http://go.worldbank.org/B53SONGPA0. 
[24] World Income Inequality Database (WIID) V 2.0b (2007) World Institution for Development and Economic Research (WIDER). Available at: http://www.wider.unu.edu/wiid/wiid.htm. 


\section{University Library}

\section{- M M I N E R VA A gateway to Melbourne's research publications}

Minerva Access is the Institutional Repository of The University of Melbourne

Author/s:

Creedy, J;Moslehi, S

Title:

Modelling the composition of government expenditure in democracies

Date:

2009-03-01

Citation:

Creedy, J. \& Moslehi, S. (2009). Modelling the composition of government expenditure in democracies. EUROPEAN JOURNAL OF POLITICAL ECONOMY, 25 (1), pp.42-55. https:// doi.org/10.1016/j.ejpoleco.2008.07.006.

Persistent Link:

http://hdl.handle.net/11343/34819 